\title{
A Proposed Framework to Investigate the User Acceptance of Personal Health Records in Malaysia using UTAUT2 and PMT
}

\author{
${ }^{1}$ Ali Mamra \\ Faculty of Information and \\ Communication Technology \\ Universiti Teknikal Malaysia Melaka \\ Melaka, Malaysia \\ ${ }^{2}$ Abdul Samad Sibghatullah \\ Faculty of Information and \\ Communication Technology \\ Universiti Teknikal Malaysia Melaka \\ Melaka, Malaysia
}

\author{
${ }^{3}$ Gede Pramudya Ananta \\ Faculty of Information and \\ Communication Technology \\ Universiti Teknikal Malaysia Melaka \\ Melaka, Malaysia \\ ${ }^{4}$ Malik Bader Alazzam \\ Faculty of Information and \\ Communication Technology \\ Universiti Teknikal Malaysia Melaka \\ Melaka, Malaysia
}

\author{
${ }^{5}$ Yasir Hamad Ahmed \\ Faculty of Information and \\ Communication Technology \\ Universiti Teknikal Malaysia Melaka \\ Melaka, Malaysia \\ ${ }^{6}$ Mohamed Doheir \\ Faculty of Information and \\ Communication Technology \\ Universiti Teknikal Malaysia Melaka \\ Melaka, Malaysia
}

\begin{abstract}
Personal Health Records (PHRs) can be considered as one of the most important health technologies. PHRs enroll the patients directly to their health decision making through giving them the authority to control and share their health information. Testing the user acceptance toward new technology is a vital process. Over the previous decades many models have been used and the latest one was UTAUT2. UTAUT2 have been widely used in e-business and gaming user acceptance researches, whereas, it has been rarely used in health field. This study proposes a combination of UTAUT2 and PMT in order to investigate the user acceptance of PHRs. Relevant factors may be added at the literature review stage. The final model will be used as a framework to investigate the user acceptance of PHRs in Malaysia.
\end{abstract}

Keywords-PHRs; User Acceptance; UTAUT2; PMT; Malaysia

\section{INTRODUCTION}

Health sector is the one of the biggest sectors in many nation[1]. Governments everywhere focus on this sector as the most necessary sector for their citizens. This concern has resulted in huge investments on health infrastructures, high monitoring on health services, and rapid implementation on technologies related to this sector [2][1]. Information technology on the other hand has been rapidly growing over the past years. E-Health as a shared part between information technology and health sector has its part of this evolution. EHealth is a global need in nowadays communities which has led many governments to announce their vision of the implementation of e-Health at each country [2][3].

\section{HIT AND MALAYSIAN VISION}

Healthcare Information Technology (HIT) can be considered as one of the major components of the modern ehealth structure. E-health involves various HIS that deals with the health information of patients such as: Electronic Health
Record (also known as EHR), Medical Health Record (Also known as EMR), and Personal Health Record (also known as PHR)[4]. Electronic Health Record is an e-health system used by any health service provider to store and provide detailed health information for a certain patient [5][6]. Electronic Medical Record refers to the records which can be accessed from various sources of information; usually involve the patient's lab tests, allergies, and diagnoses [7]. Personal Health Record is a record which can be accessed from the patient himself in order to manage his health record, save new information, share information among more than one health provider, and emergency cases such as traveling or disasters[8]. The importance of the HIT motivates many governments to announce their vision related to the adoption of HIT which can be considered as the backbone of the health informatics. It also reflects the striving toward establishing new departments and issuing new rules and acts that could help in controlling the health information obtained from patients[9].

According to Malaysia's Health report [10], The health vision of the Malaysian Ministry of Health says that:

"Malaysia is to be a nation of healthy individuals, families and communities, through a health system that is equitable, affordable, efficient, technologically appropriate, environmentally-adaptable and consumer-friendly, with emphasis on quality, innovation, health promotion and respect of human dignity and which promotes individual responsibility and community participation towards an enhanced quality of life".

Malaysia has its own vision to adopt the PHRs in the near future; according to the [11] Malaysian Healthcare is going to adopt a USB-based PHR within the next five years, which reflects the intention to adopt electronic PHRs in the future. Regarding to the use of the PHRs in Malaysia in the 
future, [11] had a vision to the PHRs to be used by a wide segment of users regardless to their being sick or healthy. Moreover, in June 2010 The Personal Data Protection Act (PDPA) has been issued by the Malaysia government as a step in the way to adopt the HIS in Malaysia; the issued act determine a group of responsibilities of the people who works at the health care sector in dealing with the medical information of the patients. It has been published for the first time in the Federal Gazette, and the act has been effective since November 2013 with new added obligations [12]. The new Act involves various obligations related to variant HISs; many issues has been listed such as privacy, security, accessibility, and commercial issues[13]. Certain actions can be taken by any patient related to their personal data protection against their healthcare providers; the patients have the right to access, update, modify, and share their health information, whereas, healthcare provider can only use these information for the therapeutic purposes[12]. These rules, act, and vision reflect the intention to adopt the HIT by the Malaysian government.

PHRs are one of many other technologies that can be listed as a consumer health informatics technology. Consumer health informatics technologies have been adopted in order to be used by the patient at home in order to control his health information using online applications such as web-based applications. These significant capabilities enrolled the patients more into making decisions related to their health status. The variant platforms used in this technology relay on the good communications between the patients and the health care provider[14]. Therefore, the internet penetration in any nation can be considered as a significant and vital aspect in describing the future of patient to physician communications. The internet penetration in Malaysia is above average in the region, almost $70 \%$ of Malaysians are able to access the Internet using various technologies such as homeliness, broadband, and mobile data. Compared to other neighbouring countries such as: Thailand, Philippine, Indonesia, Viet Nam, and except Singapore, Malaysia has the highest Internet penetration in the region. The usage of the Internet by gender in 2014 was almost equal; 51.4 per cent were males, and 48.6 per cent were females, which reflects the wide spread of the technology among citizens from both genders. Laptops were the most preferred way to access the Internet by a computer in $2014 ; 21.8 \%$ used personal computer to access the Internet, $34.1 \%$ used tablets, whereas 52.8 used laptops Internet usage by age vary from year to another, young people has the heist percentage, whereas, elderly people penetration has increased from $5.3 \%$ in 2013 to $7.3 \%$ in 2014 [15]. This is another significant aspect that should help to facilitate the adoption of PHRs in Malaysia.

\section{PERSONAL HEALTH RECORDS (PHRS)}

PHRs are electronic medical records that involve information about the patient such as personal information, lab test, diet information, medical history, and other medical information which can be accessed and maintained by the patients themselves with the ability to share this information with their health care providers in a private, convenient, and secure manner[16][17], [18], [19], and [9]. A common well- known and unified definition of PHRs in not yet decided; many different organizations gave various definitions of PHR depending on the functions and the role of the PHR decided by these organizations[20]. Over the previous years, many institutions such as the Markle Foundation, the American Health Information Management Association (AHIMA), and the National Alliance for Health Information Technology (NAHIT) have addressed the importance of the PHRs and the wide adoption of the technology in many nations[21].

According to Markle Foundation PHRs defined as:

"The Personal Health Record (PHR) is an Internet-based set of tools that allows people to access and coordinate their lifelong health information and make appropriate parts of it available to those who need it"'[22].

According to the American Health Information Management Association (AHIMA), PHRs can be defined as:

"An electronic, universally available, lifelong resource of health information needed by individuals to make health decisions, individuals own and manage the information in the PHR, which comes from health care providers and the individual. The PHR is maintained in a secure and private environment, with the individual determining rights of access. The PHR is separate from and does not replace the legal record of any provider" [23].

According to the National Alliance for Health Information Technology (NAHIT), PHRs can be defined as:

"An electronic record of health-related information on an individual that conforms to nationally recognized interoperability standards and that can be drawn from multiple sources while being managed, shared, and controlled by the individual" [24].

PHR is one of the newest services in the e-health field which enrol the patient directly to make decision related to his health information and status. One of the most important advantages of the PHR is that; patients are able to access, update, and share their medical information such as blood pressure, diabetes, spirometry, or any other info with their health care providers or others [4]. These features save a lot of patients' time and efforts since they do not have to visit their health service provider every time in order to modify their health record. Therefore, PHR can be considered as one of the most important health services which have not been applied in many countries yet [25]. On the other hand, the normal meetings between patients and professionals may not involve enough information about the patient; patient may forget or hide some information for many reasons, some patient may feel shy from reviling some information. In addition to this, the limited time of the meeting may not be enough for the information exchange between the professional and his patient. Therefore, it is important for both the patient and the professional to start the information exchange among them using specific tools[26]. Thus, PHR is needed to be adopted in any nation since it has the ability to enhance the information exchange between the patient and the healthcare provider, which will reflect positively on the patient to physician relationship. 
The important characteristics of PHR; the ability to access medical information, the ability to modify medical information, and the information sharing have been reviling many concerns regarding to the ease of use, privacy, and user attitude toward this technology. The ease of use is a significant issue especially to those elderly people who have not good experience with technology. Privacy on the other hand has a significant influence on patient decision since they might not have a clear vision about the level of security applied in such technologies, and the laws that guarantee their rights to be secured and to their information to be private [8]. The user acceptance of the technology is a key to success; investigating the user acceptance and behavioural intention toward new technology can be considered as a critical issue[27]. Testing the user acceptance of PHR in certain society may revile the future of the interaction with this technology and prevent certain problems that the technology may face in the future.

\section{USER ACCEPTANCE THEORY}

According to [28]; investigating the user acceptance toward a new technology, goods, or services plays a significant role in deciding the future of the interaction between the user and the technology, goods, or services in the future. Along the previous decades, many theories and models have been introduced in order to describe and investigate the factors that may affect the user acceptance toward new technology. Technology Acceptance Model (TAM) has been introduced by [29], Theory of Reasoned Action (TRA)
(Fishbein et al. 1975), Theory of Planned Behaviour (TPB) which can be considered as one of the first theories that describe the behavioural intention toward technology [30], Innovation Diffusion Theory (IDT) (Rogers 1995), and many other models.

\section{A. Unified theory of acceptance and use of technology (UTAUT)}

UTAUT has been introduced by [31] as a unification of eight models have been widely used in previous studies. The UTAUT involves a detailed analysis that describes the factors affecting the user acceptance of a certain item. UTAUT explained about 70 percent of the variance in behavioural intention to use a technology and about 50 percent of the variance in technology use [27]. Since 2003, UTAUT alone, a combination of UTAUT and other models, or an extended version of UTAUT has been widely applied in many fields and various studies that aim to investigate the user acceptance toward new technology[32]. UTAUT is generally consisting of four major parts; Performance Expectancy (PE) which describes the degree of benefit gained by an individual using certain technology, Effort Expectancy (EE) describes the ease of use of a certain technology by an individual, Social Influence (SI) which describes the effective motivation by others (family, friends, or colleagues) to an individual intended to use certain technology, and Facilitating Conditions (FC) which describes the facilities available which may support the use of the new technology by an individual (Venkatesh et al. 2003).

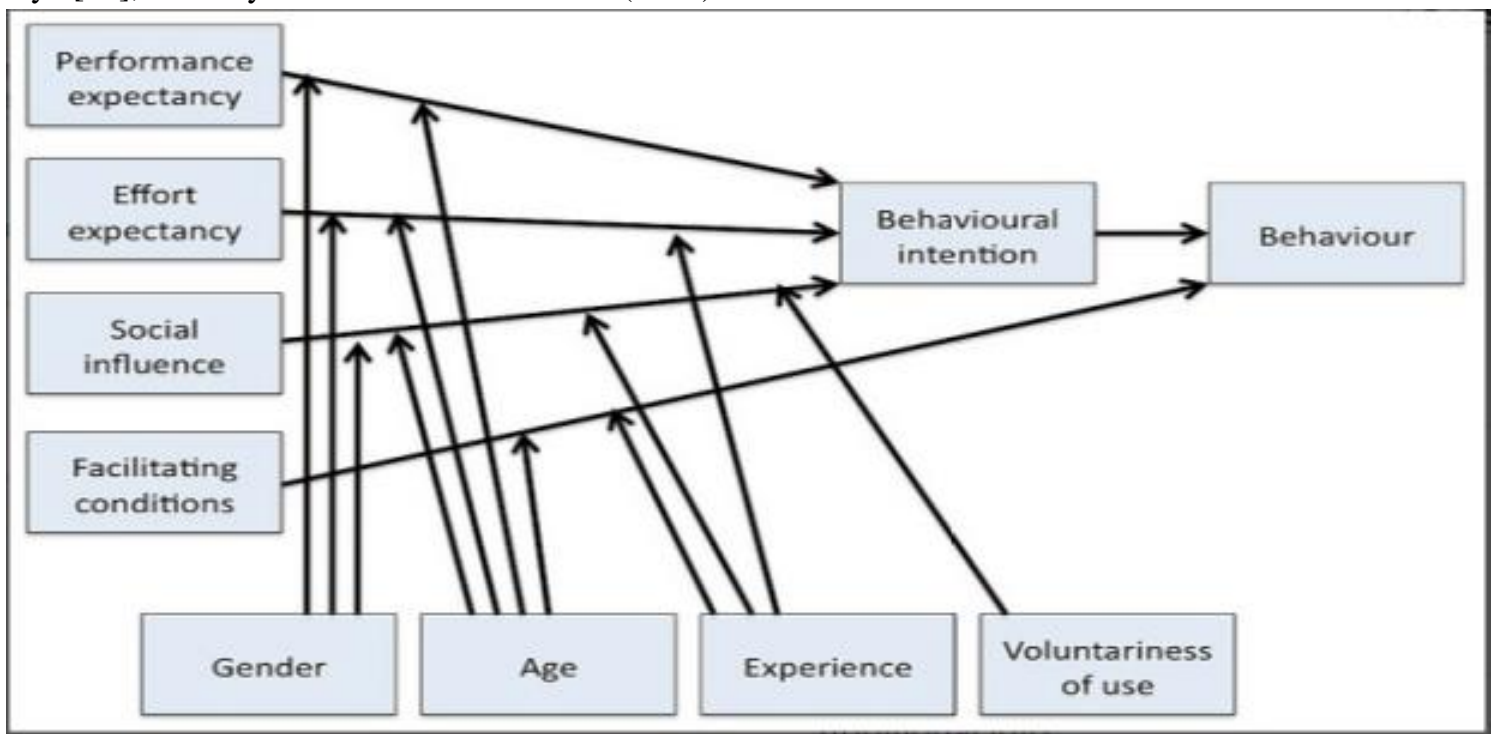

Fig. 1. UTAUT

As shown in (Figure 1), UTAUT relationships represented by variant individual variables such as: gender, age, experience, and voluntariness of use.

\section{B. UTAUT2}

Despite the huge success of the UTAUT, [27] have introduces UTAUT2 as an enhanced version of UTAUT that involves new three elements which are: Price Value (PV), Hedonic Motivation (HM), and Habit (HT), each new element has a significant influence on the behavioural intention of users. Hedonic Motivation (HM) describes the level of enjoyment of the technology used by an individual; this factor has been used in previous models such as TAM as intrinsic motivation. Price Value (PV) describes the price influence on choosing a new technology; people generally looking for the price to performance aspect in order to make a decision on using a new technology. Habit (HT) describes the habitual behavior of the user of the new technology; being used to use similar technologies will motivate an individual to use the new technology. HT can be considered as one of the most 
significant factor in predicting the use of the technology in the near futureSince its introduction in 2012 UTAUT2 has been widely applied in many fields except a noticeable lack in the health sector[5]. However, UTAUT2 has a higher accuracy that may enhance its ability to investigate the user acceptance and the behavioural intention toward new technology, and it has been recommended by its author to be applied in different fields, studies, and countries in order to come out with the highest accurate results[27].

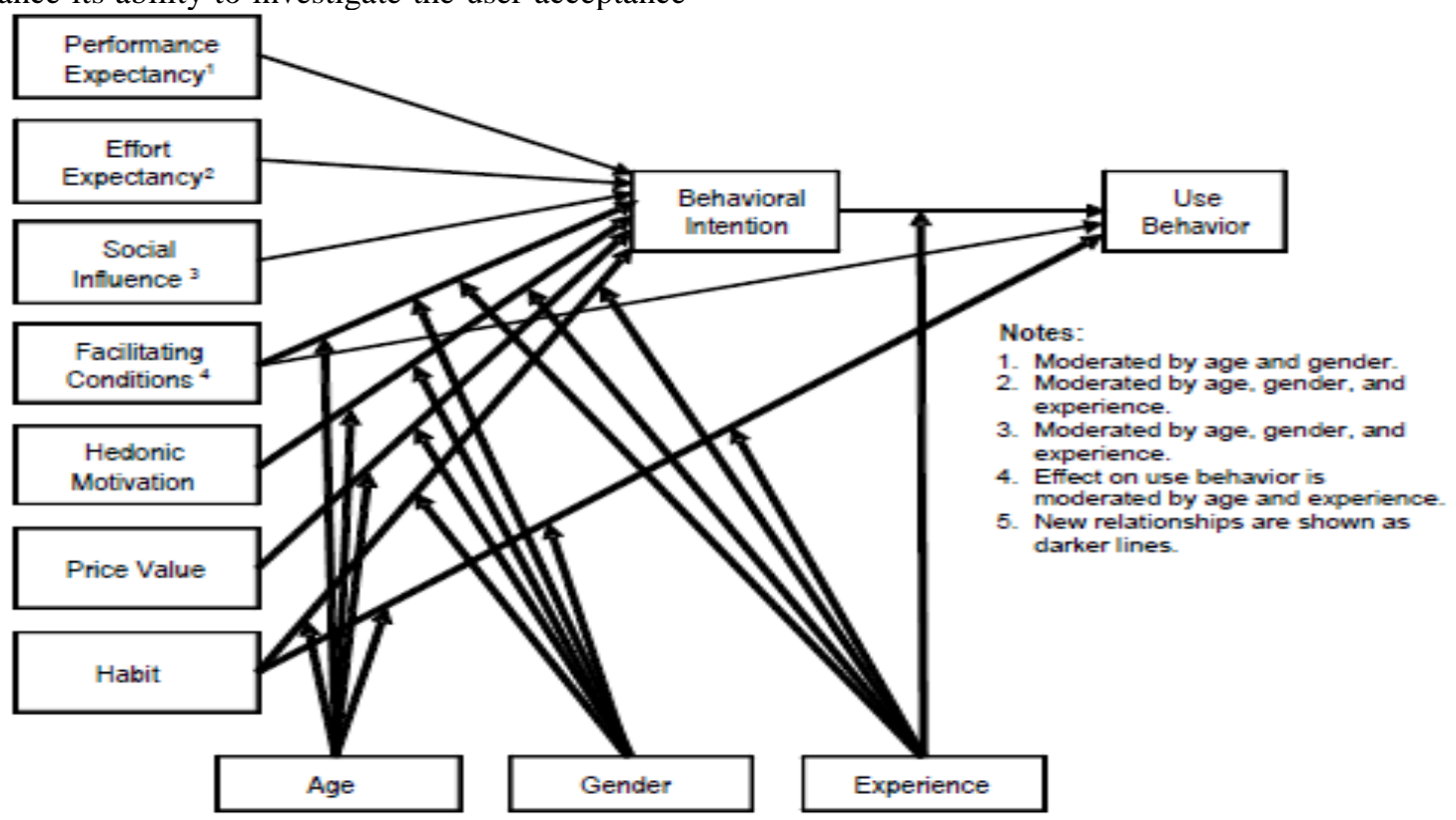

Fig. 2. UTAUT2

\section{Proposed model}

UTAUT and UTAUT 2 have been widely applied in many fields such as e-business, e-learning, gaming, and mobile technologies[33], and [32]. Few studies discussing the user acceptance of health care services and HIT have been done using UTAUT2[33]. UTAUT2 has higher accuracy in investigating the user acceptance and behavioural intention of a user toward new technology[27]. On the other hand, investigating the behavioural intention toward healthcare technologies has been done over the past years using various models. The most widely applied model in this field is the Protection Motivation Theory (PMT). PMT discusses the individual's vision regarding to the vulnerability and severity of certain threat, and what is the capability of these users to deal with such threat which will reflect the behavioural intention of these users toward the new technology[34]. According to [35], adding threat appraisal endogenous variable from PMT on his unified model have found to be significantly affecting the user acceptance and the behavioural intention toward new health technology. Thus, and based on the results appeared on previous studies, this research proposes an enhancement of UTAUT2 by adding the Threat Appraisal endogenous variable from PMT which may have a significant influence on the user acceptance and behavioural intention toward e-health technologies (See Table 1).
TABLE. I. (UTAUT2 AND PMT COMPARISON)

\begin{tabular}{|l|l|l|}
\hline Endogenous Variables & UTAUT 2 & PMT \\
\hline Performance Expectancy & Available & Available \\
\hline Effort Expectancy & Available & Not-Available \\
\hline Social Influence & Available & Not-Available \\
\hline Facilitate Conditions & Available & Available \\
\hline Price Value & Available & Not-Available \\
\hline Hedonic Motivation & Available & Not-Available \\
\hline Habit & Available & Not-Available \\
\hline Threat Appraisal & Not-Available & Available \\
\hline
\end{tabular}

Other factors such as security, privacy, and trust might be added after reviewing related studies.

\section{PROBLEM STATEMENT}

The rapid development in ICT and HIT has reviled new needs such as the use of Personal Health Records as a part of the e-health. The authority of accessing and modifying the health records by patients has great advantages in term 
of saving time and efforts. On the other hand, accessing these services by patients may generate doubts about the performance, use, and the privacy issues.

Testing the user acceptance of new technology in certain society may revile the future of the interaction between the user and the new technology. UTAUT is one of the most desirable models in order to be used to test the user acceptance of a certain technology. UTAUT has been used and applied in few studies related to PHRs. On the other hand, UTAUT2 have not been yet applied in the PHRs research area despite its enhanced structure. Therefore, this research proposes UTAUT2 to be used as the main model to investigate the user acceptance of PHRs in Malaysia. UTAUT and UTAUT2 have been introduced as a business model; therefore, some features must be added in order to fit the healthcare field. PMT on the other hand has been widely used in investigating the behavioural intention to use HIT. The most significant component related to the HIT in this model is the "Threat Appraisal" variable.

This research will focus on those features that affect the user acceptance of Personal Health Record in Malaysia by enhancing the UTAUT2 in order to be suitable for healthcare sector. A combination of UTAUT2 and PMT will be proposed as a result of this research.

\section{RESEARCH OBJECTIVES}

The main objectives of this research are:-

1) Deciding the factors affecting the user acceptance of PHR in certain society.

2) Analyzing the impact of these factors.

3) Developing an enhanced model in order to analyze these factors.

\section{EXPECTED OUTCOMES}

The expected outcomes of this research are:-

1) A list of factors that affect the PHR acceptance in Malaysia.

2) The impact of these factors on the user acceptance of PHR in Malaysia.

3) An enhanced user acceptance testing model.

\section{SCOPE OF RESEARCH}

The scope of this research revolves around the factors affecting technology acceptance of Personal Health Record. The factors involved in this research are the technology acceptance factors adopted from the UTAUT2 and the factors added by this research and how they affect the user acceptance and the behavioural intention toward the Personal Health Record.

\section{LIMITATIONS}

The main limitations will be the lack of resources related to the PHRs acceptance research field which has been found to be few in comparison with other fields such as EHR, and EMR. On the other hand, the resources describing the history of e-health in Malaysia are insufficient.

\section{Contribution to The KnOWLEDGE}

This research contribution will be:-

1) Illustrating the Obstacles facing the adoption of PHRs in Malaysia.

2) The concerns related to the use of PHRs in Malaysia.

3) The current capabilities of adopting the PHRs in Malaysia.

4) The cultural differences that may affect the use of PHRs in Malaysia.

5) The desired components of UTAUT2 in healthcare field.

6) A unique combination represented in an enhanced model of user acceptance toward new technology to be used in healthcare field.

\section{RESEARCH METHODOLOGY}

\section{A. Introduction}

Over the previous decades, researchers from all over the world have tried to define the users' needs which reflect their acceptance of any product. Several theories and models have been introduced in order to investigate the user acceptance of a specific product. The results of these researches were group of a different models reflects the vision of their founders. Many models and theories such as:-

1) Theory of reason Action (TRA)

2) Technology acceptance model (TAM)

3) Motivational model (MM)

4) Theory of planned behaviour (TPB)

5) Combined TAM and TPB (C-TAM-TPB)

6) Model of PC Utilization MPCU

7) Innovation Diffusion Theory (IDT)

8) Social Cognitive Theory (SCT)

All the above models and theories have been combined and unified in order to have a unified model with effective tools that can describe the user acceptance in the optimum way. The unification of these models and theories has led to the introduction of UTAUT "Unified Theory of acceptance and Use of Technology“"[31].

Figure 1 and 2 illustrate the relationships that exist in the UTAUT and UTAUT2 model. The UTAUT model has four components, PE which refers to Performance expectancy, EE, which refers to effort expectancy, SI which refers to social influence, and FC which refers to facilitating conditions. Whereas, UTAUT2 has three extra important components which are: Hedonic Motivation, Price Value, and Habit beside the above mentioned components in UTAUT. The components of these models (also known as endogenous variables) are the technology intention to use and behaviour. There are other four moderators namely age, experience, gender and voluntariness. [31] and [27].

UTAUT and UTAUT2 have been introduced as an ebusiness user acceptance model; therefore, adding some features to this model will enhance it in order to be used in PHRs research. 


\section{B. Methodology}

Methodology is the "a way of thinking and studying social reality" as defined by [36], they also suggested that quantitative methods might be used appropriately in any research paradigm, which is defined as the basic belief system or worldview that guides the investigator. The issue of appropriate method is only secondary to the choice of the appropriate paradigm [36]. In this research (See Figure 3) the information gathered from the literature review will guide us to find out the issues that affects the user acceptance of Personal Health Records in Malaysia. These new factors or issues will be added to the desired model in order to fit the ehealth field.

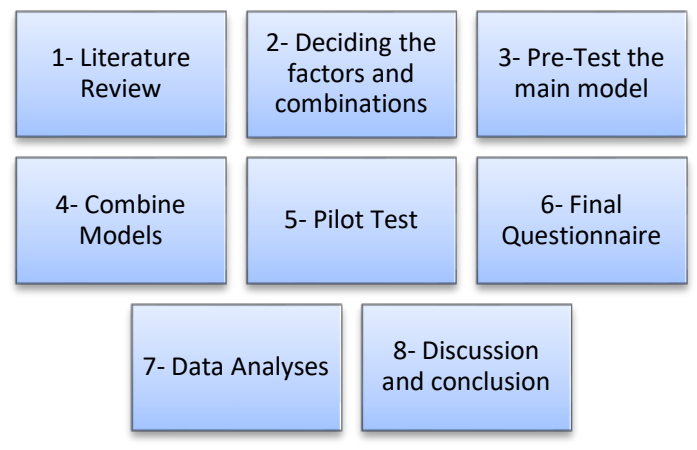

Fig. 3. Research Methodology

Choosing between qualitative or quantitative study still a concern, researchers from both parties have their own reasons to prefer any. This study focuses on examining the user acceptance of PHRs, and since it is targeting a wide segment of users, the quantitative study is preferred.

The obtained data from the literature review regarding to the factors affecting the acceptance of PHRs in related works will be analysed in order to decide the primitive questionnaire. After finishing the review analyses, the new model creating will start by three major phases which are: Pre-Test, PilotTest, and the Final Questionnaire.

First of all, a pre-test process will be done to examine the undesired components in UTAUT2 in order to be ignored at the pilot test stage; pre-test will be held in order to find out the undesired components which do not have any influence on the user acceptance toward new technology in PHRs research field.

The second stage will involve a pilot test of the combination in order to find out the suitability of the questions that will be used in the final stage which is the final questionnaire; pilot test process is a questionnaire done using small sample size in order to find out any problems or missing issues in the final questionnaire.

Finally, a quantitative study represented in a modified questionnaire will be held as a result of the pilot test process. The modified questionnaire will be distributed to a sample of expected PHR users in order to be analysed using specific tool (e.g. SPSS) and provide the user acceptance details of PHR. The findings of the final questionnaire results analysis will reveal the user acceptance of PHR in Malaysia, the capabilities to adopt this technology, and the obstacles may face the adoption of PHRs in Malaysia.

\section{CONCLUSION}

This study aims to investigate the user acceptance toward PHRs in Malaysia. Using suitable testing model may increase the accuracy of the obtained results. UTAUT2 is one of the most accurate user acceptance testing models. Adding some features to increase the suitability of this model to the health field may result in higher accurate results. As a beginning, threat appraisal will be added to the UTAUT2, some other factors such as privacy and trust may be added after reviewing a number of related studies.

\section{ACKNOWLEDGMENT}

This work was supported by Centre of Research and Innovation Management (CRIM) and Faculty of ICT, Universiti Teknikal Malaysia Melaka, Hang Tuah Jaya, 76100 Durian Tunggal, Melaka, Malaysia.

\section{REFERENCES}

[1] E. Liikanen, "“The Importance of eHealth in Europe," World Health, no. December, 2003.

[2] L. M. Hernandez, "Health Literacy, e-Health, and Communication: Putting the Consumer First: Workshop Summary." 2009.

[3] J. M. McGrath, N. H. Arar, and J. A. Pugh, "The influence of electronic medical record usage on nonverbal communication in the medical interview.," Health Informatics J., vol. 13, no. 2, pp. 105-118, 2007.

[4] L. Kumar, K. Sharanie, and D. Jaspaljeet, "iMedPub Journals Barriers to Adoption of Consumer Health Informatics Applications for Health SelfManagement Abstract," Heal. Sci. J. ISSN 1791-809X, vol. Vol. 9 No., pp. 1-7, 2015.

[5] M. B. Alazzam et al., "Ehrs Acceptance in Jordan Hospitals By Utaut2 Model: Preliminary Result," J. Theor. Appl. Inf. Technol., vol. 3178, no. 3, pp. 473-482, 2015.

[6] A. I. Muhamad, M. R. M. Rosman, M. I. Ramzi, and M. I. M. Salleh, "Conceptualizing Medical Application Software for Managing Electronic Health Records (EHR) and Cash Flow Management in Private Clinics,” Int. J. Innov. Manag. Technol., vol. 3, no. 2, pp. 151$155,2012$.

[7] K. Noraziani et al., "An overview of electronic medical record implementation in healthcare system: Lesson to learn," World Appl. Sci. J., vol. 25, no. 2, pp. 323-332, 2013.

[8] HealthInsight Utah, H. Mexico, and Others, "PHR Ignite Environmental Scan: The Personal Health Record Landscape of Utah and New Mexico," no. 212050, 2013.

[9] G. Demiris, "New era for the consumer health informatics research agenda," vol. 1, no. 1, pp. 13-16, 2012.

[10] Moh, "Dealing With Adolescents Using the Headss Assessment," Malaysia's Heal., pp. 89-96, 2008.

[11] S. Ponnudurai, "Mobile Health Records in Malaysia," Asia Biotech, vol. 14, no. 5\&6, pp. 32-33, 2010.

[12] Norton Rose Fulbright, "Global Data Privacy Directory," Glob. data Priv. Dir., vol. July, 2014.

[13] T. J. Kobus III and G. S. Zeballos, "2014 International Compendium of Data Privacy Laws," 2015.

[14] L. Calvin et al., "Factors affecting home care patients' acceptance of a web-based interactive self-management technology," pp. 51-59.

[15] MCMC, "Communications and Multimedia Pocket Book of Statistics," J. Chem. Inf. Model., vol. 53, no. 9, pp. 1689-1699, 2015.

[16] E. Agrawal, "ACCEPTANCE AND USE OF PERSONAL HEALTH RECORD: FACTORS AFFECTING PHYSICIANS' PERSPECTIVE," Indiana Univ., vol. December, p. 113, 2010. 
[17] J. Barlow, W. Crawford, and D. Lansky, The value of personal health records. A joint position statement for consumers of health care., vol. 137. 2008.

[18] J. Cruickshank, "Putting patients in control ? Personal Health Records," no. September, 2012.

[19] Daglish E, "a Matter of Trust Electronic Personal Health Records : a Matter of Trust," McMaster Univ., p. 149, 2013.

[20] Miller H.D, Yasnoff W.A, and B. H.A, "Personal health records: the essential missing element in 21 st century healthcare.," Healthc. Inf. Manag. Syst. Soc., 2009.

[21] K. Jeongeun, “The Personal Health Record," Heal. Informatics Res., vol. 107, no. 9, p. 27, 2011.

[22] Markle Foundation, "The Personal Health Working Group Final Report," Markle Found., p. 58, 2003.

[23] L. A. Wiedemann, "Practice brief. The role of the personal health record in the EHR," J Ahima, vol. 76, no. 7, p. 64A-64D, 2005.

[24] NAHIT, "Defining Key Health Information Technology HIT Terms," Natl. Coord. Heal. Inf. Technol., 2008.

[25] C. J. Gearon, "Perspectives on the future of personal health records," no. June, pp. 1-29, 2007.

[26] M. Bliemel and K. Hassanein, "Consumer satisfaction with online health information retrieval: a model and empirical study," E-Service J., vol. 5, no. 2, pp. 53-83, 2006.

[27] V. Venkatesh, J. Thong, and X. Xu, "CONSUMER ACCEPTANCE AND USE OF INFORMATION TECHNOLOGY : EXTENDING THE UNIFIED THEORY,” MIS Q., vol. 36, no. 1, pp. 157-178, 2012.
[28] V. Venkatesh, F. D. Davis, and M. G. Morris, "Dead Or Alive? The Development, Trajectory And Future Of Technology Adoption Research," J. Assoc. Inf. Syst., vol. 8, no. 4, pp. 267-286, 2007.

[29] F. Davis, R. Bagozzi, and P. Warshaw, "User acceptance of computer technology: a comparison of two theoretical models," Management science, vol. 35, no. 8. pp. 982-1003, 1989.

[30] I. Ajzen, "The theory of planned behavior," Orgnizational Behav. Hum. Decis. Process., vol. 50, pp. 179-211, 1991.

[31] V. Venkatesh, M. Morris, G. Davis, and Fred Davis., "User acceptance of information technology: Toward a unified view," MIS Q., vol. 27, no. 3, pp. 425-478, 2003.

[32] A. Chang, "UTAUT AND UTAUT 2: A REVIEW AND AGENDA FOR FUTURE RESEARCH," J. WINNERS , Vol., vol. 13, no. 9, pp. 106-114, 2012.

[33] M. B. Alazzam, A. S. H. Basari, A. S. Sibghatullah, and M. Doheir, "Review of Studies with UTAUT2 as Conceptual Framework," MAGNT Res. Rep., vol. 3, no. 3, pp. 620-629, 2015.

[34] R. W. Rogers, "Cognitive and physiological processes in attitude change: A revised theory of protection motivation," Soc. Psychophysiol., no. July, pp. 153-176, 1983.

[35] Y. Sun, N. Wang, X. Guo, and Z. Peng, "Understanding the Acceptance of Mobile Health Services: a Comparison and Integration of Alternative Models," J. Electron. Commer. Res., vol. 14, no. 2, pp. 183-200, 2013.

[36] A. Strauss and J. Corbin, Basics of Qualitative Research: Techniques and Procedures for Developing Grounded Theory, vol. 3. 2008. 